\title{
Corrective Lens
}

National Cancer Institute

\section{Source}

National Cancer Institute. Corrective Lens. NCI Thesaurus. Code C87188.

A lens generally worn in front of the eye, mainly used to treat myopia, hyperopia, astigmatism, and presbyopia. This includes glasses, contact lenses, and intraocular implanted lenses. 